\title{
Modeling of cooling process of hydroaluminosilicate materials
}

\author{
V.V. Sobchenko (ORCID 0000-0002-8575-7584), V.A. Zhaivoronok (ORCID 0000-0002-9669-2843), \\ H.O. Sobchenko (ORCID 0000-0002 2411-9562)
}

The Gas Institute of the NAS of Ukraine, str. Degtyarivska, 39, Kyiv, 03113, Ukraine

Tel.: +380962972878

E-mail:via_sobchenko@ukr.net

Article info: received 09.09.2021, revised 24.09.2021, accepted 29.09.2021

Sobchenko, V.V., Zhaivoronok, V.A., Sobchenko, H.O. (2021) Modeling of cooling process of hydroaluminosilicate materials 3(52), DOI: 10.26909/csl.3.2021.3

Porous thermal-insulation materials are widely used in building industry, the advantages of which are cheapness and efficiency. Their commercial appearance is also important in their implementation. Porous thermal-insulation materials to prevent sticking can be packaged only after cooling and after the main thermal processes and classification.

The process of cooling porous hydroaluminosilicate materials by the method of modeling with the subsequent check on the laboratory equipment with a fluidized bed is investigated in the work. The main thermal process takes place at a temperature of about $300{ }^{\circ} \mathrm{C}$. The cooling time of the porous material to a temperature of $20^{\circ} \mathrm{C}$, which is about 20 seconds, is calculated, and the need to ensure this time in its classification is indicated. This model allows you to determine with sufficient accuracy the cooling time for particles of different diameters and temperatures.

The process of cooling the obtained thermal-insulation material in the production technology occurs simultaneously with its hydrodynamic classification in the cascade classifier of the fluidized bed. It is important to determine the required cooling time of the spherical hydroaluminosilicate material to temperatures close to $20{ }^{\circ} \mathrm{C}$ and to ensure the presence of particles in the apparatus during this time.

Comparison of experimental data with the results of the mathematical model shows the results with an error of $10 \%$. There is a slight increase in the minimum residence time of a single granule obtained experimentally compared with the calculated.

Key words: porous heat-insulating materials, rottenstone, heat treatment, fluidized bed.

\section{Моделювання процесу охолодження гідроалюмосилікатних матеріалів}

\author{
В.В. Собченко, В.А. Жайворонок, Г.О. Собченко
}

Інститут газу НАН Украӥни, Київ, Украӥна

Широким попитом у будівництві користуються пористі теплоізоляційні матеріали, перевагами яких є дешевизна і ефективність. При їх реалізації також є важливим їх товарний вигляд. Для запобігання злипанню пористі теплоізоляційні матеріали можливо упаковувати тільки після охолодження та кінцевої класифікації.

В роботі досліджено процес охолодження пористих гідроалюмосилікатних матеріалів методом компьтерного моделювання з подальшою перевіркою на лабораторному обладнанні з псевдозрідженим шаром. Основний термічний процес відбувається при температурі близько $300{ }^{\circ} \mathrm{C}$. Розраховано час охолодження пористого матеріалу до температури $20^{\circ} \mathrm{C}$, що складає близько 20 секунд. Вказано на необхідність забезпечення цього часу при його класифікації. Вказана модель дозволяє з достатньою точністю визначати час охолодження для частинок різного діаметра і температури.

\section{Вступ}

В розрізі сучасного розвитку будівельної галузі України і використання великої кількості будівельних матеріалів іноземного виробництва $€$ необхідність розроблення нових чи модернізації існуючих технологій виробництва вітчизняних теплоізоляційних матеріалів з метою здешевлення та покращення їх споживчих властивостей. Виробництво більшості будівельних матеріалів 
пов'язане 3 витратами значної кількості теплової і електричної енергій, що веде до здорожчання продукції. В першу чергу, це пов'язано з необхідністю високотемпературної (900 - $1000{ }^{\circ} \mathrm{C}$ і вище) термообробки сировинних матеріалів [1]. Тому зрозумілим є прагнення до використання технологій, що забезпечують отримання теплоізоляційних будівельних матеріалів без застосування високотемпературної термообробки. Важливе значення мають також споживчі властивості таких матеріалів, що забезпечують мінімальні теплові втрати будівель і споруд при використанні в будівельній теплоізоляції [2].

Інститутом газу НАН України проводяться дослідження процесів при одержанні теплоізоляційних матеріалів, в тому числі пористих гідроалюмосилікатних матеріалів, з розробленням технологій їх виробництва [3]. Одержання пористих теплоізоляційних гідроалюмосилікатних матеріалів характеризується низькотемпературною термообробкою (близько $400{ }^{\circ} \mathrm{C}$ ) сировинних матеріалів, що $є$ запорукою відносної дешевизни продукту.

В технології виробництва пористих теплоізоляційних матеріалів важливим аспектом $є$ необхідність надання товарного вигляду для продажу. Це здійснюється шляхом пакування одержаного, сортованого за розмірами, матеріалу в бігбеги тощо. Пакування можливе тільки у випадку належного охолодження після основних теплових процесів, як правило, до температур, близьких $20{ }^{\circ} \mathrm{C}$.

Мета роботи. Провести модельні дослідження можливості одержання теплоізоляційних матеріалів широкого вжитку на основі пористих гідроалюмосилікатів.

\section{Матеріали та методи дослідження}

Пористі гідроалюмосилікатні матеріали одержують із сировинного матеріалу трепелу - пухкої або слабо зцементованої, тонкопористої опалової породи, що є розповсюдженою та території України 3 хімічним складом: $\mathrm{SiO}_{2}-79 \ldots 85 \%, \mathrm{Al}_{2} \mathrm{O}_{3}-5 \ldots 6,7 \%$, $\mathrm{Fe}_{2} \mathrm{O}_{3}-2,3 \ldots 3,7 \%, \mathrm{CaO}+\mathrm{MgO}-1,5 \ldots 4,5 \%$. Трепел для будівельної індустрії є відносно новим видом сировини $з$ невеликим досвідом його застосування. В той же час він $є$ цінною сировиною для отримання напівфабрикатів у виробництві пористих теплоізоляційних матеріалів.

Опис технології розробленого пористого теплоізоляційного матеріалу на основі гідроалюмосилікатів представлено в [4]. Його одержують використовуючи технологію псевдозрідженого шару в температурному діапазоні $300-360^{\circ} \mathrm{C}$. Зовнішній вигляд пористого теплоізоляційного матеріалу представлено на рис. 1.

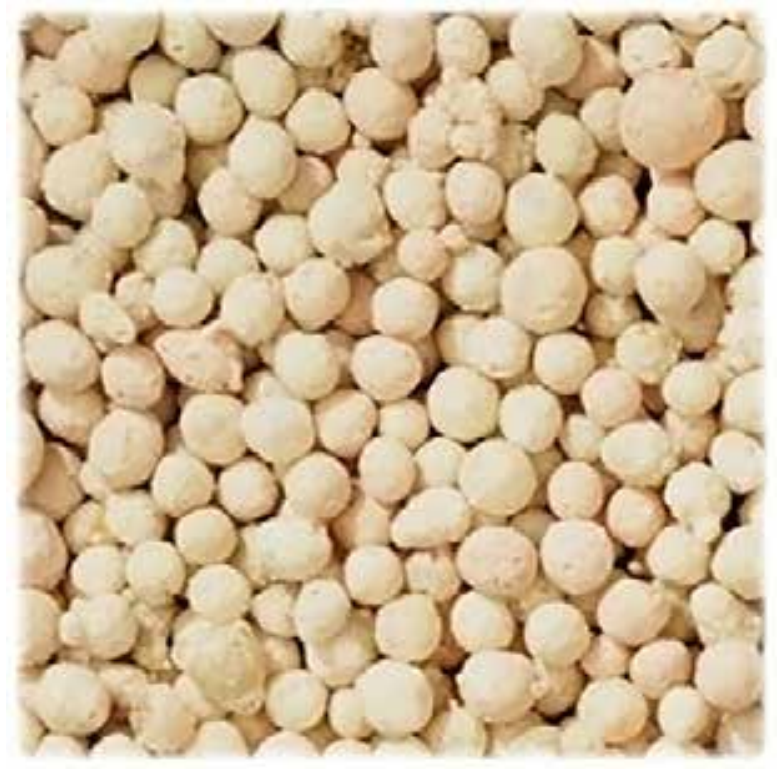

Рис. 1. Зовнішній вигляд пористого теплоізоляційного матеріалу на основі гідроалюмосилікатів

Процес охолодження одержаного теплоізоляційного матеріалу в технології виробництва відбувається одночасно з його гідродинамічною класифікацією в каскадному класифікаторі псевдозрідженого шару. Важливе визначення необхідного часу охолодження гідроалюмосилікатного матеріалу сферичної форми до температур близьких $20^{\circ} \mathrm{C}$ і забезпечення перебування частинок в апараті протягом цього часу.

Фізична модель процесу охолодження пористої сферичної кулі представлена в [5].

Розглянемо охолодження кулі в середовищі $з$ постійною температурою та постійним коефіцієнтом тепловіддачі на іiі поверхні. У початковий момент часу при $\tau=0$ всі точки кулі радіусом $R$ мають однакову температуру $T_{z p 0}$. За заданих умов температура для будь-якої точки кулі буде функцією тільки часу та радіусу. Необхідно знайти розподіл температури всередині кулі.

За початкове беремо диференційне рівняння теплообміну

$$
\frac{\partial t}{\partial \tau}+\frac{\partial t}{\partial x} \omega_{x}+\frac{\partial t}{\partial y} \omega_{y}+\frac{\partial t}{\partial z} \omega_{z}=a\left(\frac{\partial^{2} t}{\partial x^{2}}+\frac{\partial^{2} t}{\partial y^{2}}+\frac{\partial^{2} t}{\partial z^{2}}\right)
$$

де $\tau$ - час; $t$ - температура середовища; $\omega$ - швидкість.

Так як конвективний теплообмін при передачі теплоти в гранулі не здійснюється, то конвективну складову ми виключаємо з рівняння. 


$$
\frac{\partial t}{\partial \tau}=a\left(\frac{\partial^{2} t}{\partial x^{2}}+\frac{\partial^{2} t}{\partial y^{2}}+\frac{\partial^{2} t}{\partial z^{2}}\right)
$$

Якщо позначити надлишкову температуру для будь-якої точки кулі $u=t_{z p}-t_{u}$ то запишемо диференціальне рівняння теплопровідності кулі в сферичних координатах [6]

$$
\frac{\partial u}{\partial \tau}=a\left(\frac{\partial^{2} u}{\partial r^{2}}+\frac{2}{r} \cdot \frac{\partial u}{\partial r}\right),
$$

Початкові умови при $\tau=0$

$u=u_{0}=T_{\text {гр0 }}-T_{u}$, для $0<r<R$.

Граничні умови:

$$
\begin{gathered}
\frac{\partial u}{\partial \tau_{r=0}}=0, \\
\frac{\partial u}{\partial \tau_{r=R}}=-\frac{a}{\lambda} \cdot u_{r=R},
\end{gathered}
$$

де $T_{\text {гр0 }}$ - початкова температура гранули, $T_{u}$ - температура охолоджуючого агента.

Для розв'язку системи рівнянь (3 - 5) використаємо метод сіток за неявною схемою.

Розіб'ємо область розрахунку на сітку:

$$
\begin{aligned}
& r_{i}=r_{0}+i h,(i=0,1,2, \ldots), h=\Delta r, \\
& t_{j}=t_{0}+j l,(i=0,1,2, \ldots), l=\Delta t .
\end{aligned}
$$

Замінимо похідні функцій кінцево-різницевими співвідношеннями [7]:

- правостороння апроксимація похідної:

$$
\left(\frac{\partial u}{\partial r}\right)_{i j}=\frac{u_{i+1, j}-u_{i j}}{h},\left(\frac{\partial u}{\partial t}\right)_{i j}=\frac{u_{i, j+1}-u_{i j}}{l},
$$

- центральна апроксимація похідної:

$$
\left(\frac{\partial u}{\partial r}\right)_{i j}=\frac{u_{i+1, j}-u_{i-1 j}}{2 h},\left(\frac{\partial u}{\partial t}\right)_{i j}=\frac{u_{i, j+1}-u_{i j-1}}{2 l}
$$

- формула для заміни похідної II порядку:

$$
\left(\frac{\partial^{2} u}{\partial r^{2}}\right)_{i j}=\frac{u_{i+1, j}-2 u_{i j}+u_{i-1, j}}{h^{2}}
$$

Правостороння апроксимація (6) використовується для (5). Центральна апроксимація (7) застосовується в диференційному рівнянні (3).

Зробимо заміну похідних за формулами (6) - (8) та зведемо подібні члени для заданої системи (3) (5), тоді вона приймає вигляд:

$$
\begin{gathered}
\frac{1}{l} u_{i, j+1}+\left(\frac{2 a}{h^{2}}-\frac{a}{h^{2}}\right) u_{i-1, j}+\left(\frac{2 a}{h^{2}}-\frac{1}{l}\right) u_{i j}- \\
-\left(\frac{2 a}{2 h r}+\frac{a}{h^{2}}\right) u_{i+1, j}=0, \\
\frac{1}{h} u_{i+1, j}+\left(\frac{\alpha}{\lambda}-\frac{1}{h}\right) u_{i j}=0, \\
\frac{1}{h} u_{i j}-\frac{1}{h} u_{i-1, j}=0 .
\end{gathered}
$$

Система рівнянь (9) - (11) розв'язується методом Гаyca.

\section{Результати та їх обговорення}

Результати моделювання зображені на рис. 2.

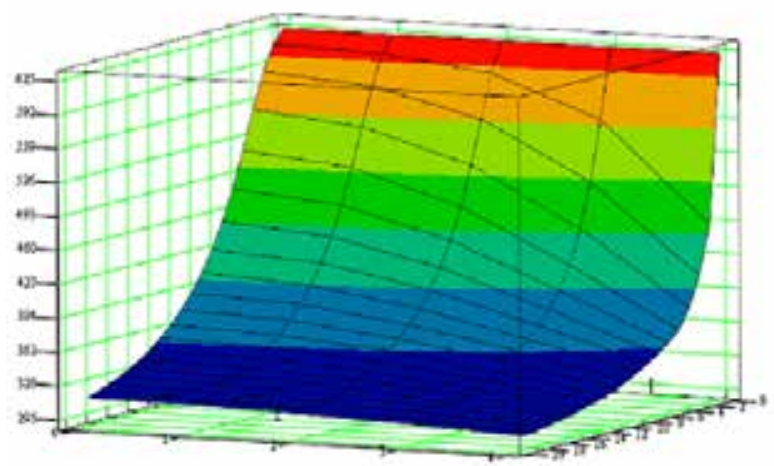

Рис. 2. Графік зміни поля температур одиничної гранули

Моделювання процесу охолодження одиничної гранули за допомогою прикладного програмного пакету Ansys дозволило отримати графічне зображення розподілу температури всередині одиничної гранули в потоці охолоджуючого агента (рис. 3).

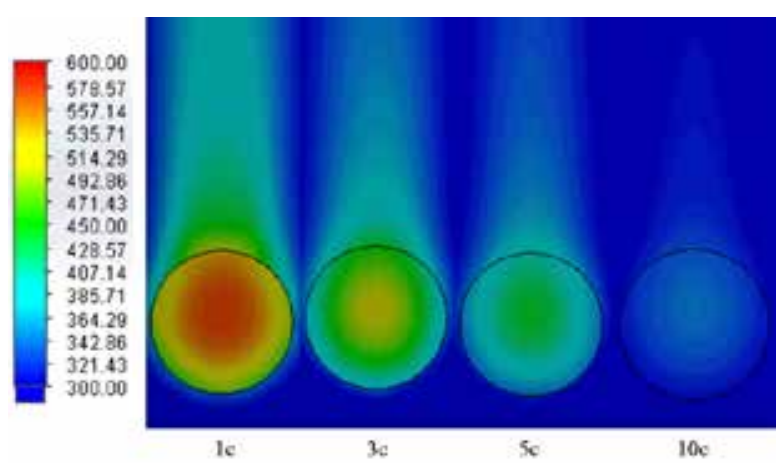

Рис. 3. Графічне зображення розподілу температури всередині одиничної гранули в потоці охолоджуючого агента 
Для експериментальної перевірки адекватності математичної моделі теплообміну при охолодженні, а саме визначення мінімального необхідного часу перебування одиничної гранули спученого гідроалюмосилікату в псевдозрідженому шарі для завершення процесу охолодження гранул, виконана серія дослідів на установці КС-01 [8].

Заздалегідь була приготовлена гранула спученого гідросилікату діаметром $d=8$ мм із вмонтованими в неї спаями термопари XK (L), що виконані 3 дроту діаметром $d_{m}=0,2$ мм у кількості 3 од. та $\epsilon$ датчиками значень температур гранули, що охолоджується. Покази поля температур гранули контролювались вторинним приладом ПВІ-0298 і зберігались на комп'ютері у вигляді текстового файлу. Схема розміщення спаїв термопар всередині гранули показана на рис. 4.

Досліди проводилися таким чином: вмикалась подача повітря на установці КС-01. Після чого в циліндр засипались, попередньо розігріті до температури $T_{2 p 0}=350{ }^{\circ} \mathrm{C}$, гранули спученого гідроалюмосилікату загальною масою 0,01 кг та середнім діаметром $d=6$ - 10 мм. Гранули спученого гідросилікату зріджувались потоком холодного повітря. В центрі псевдозрідженого шару розміщувалась гранула з вмонтованими термопарами. Фіксувалась зміна температурного поля спученої гранули.

Результати дослідів наведені у графічному вигляді на рис. 5. 3 графіків видно, що характер зміни тем-

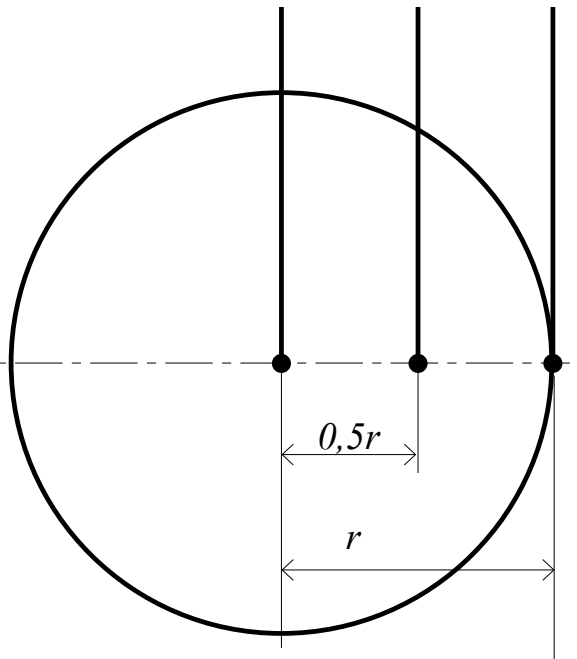

Рис. 4. Схема розміщення спаїв термопар всередині гранули спученого гідросилікату

пературного поля гранули спученого гідросилікату відповідає представленням про процес теплообміну, покладеним в основу проведених розрахунків.

Порівняння експериментальних даних 3 результатами математичної моделі показує результати 3 похибкою в межах $10 \%$. Виявляється незначне збільшення мінімального часу перебування одиничної гранули отриманих експериментальним шляхом порівняно з розрахунковими.

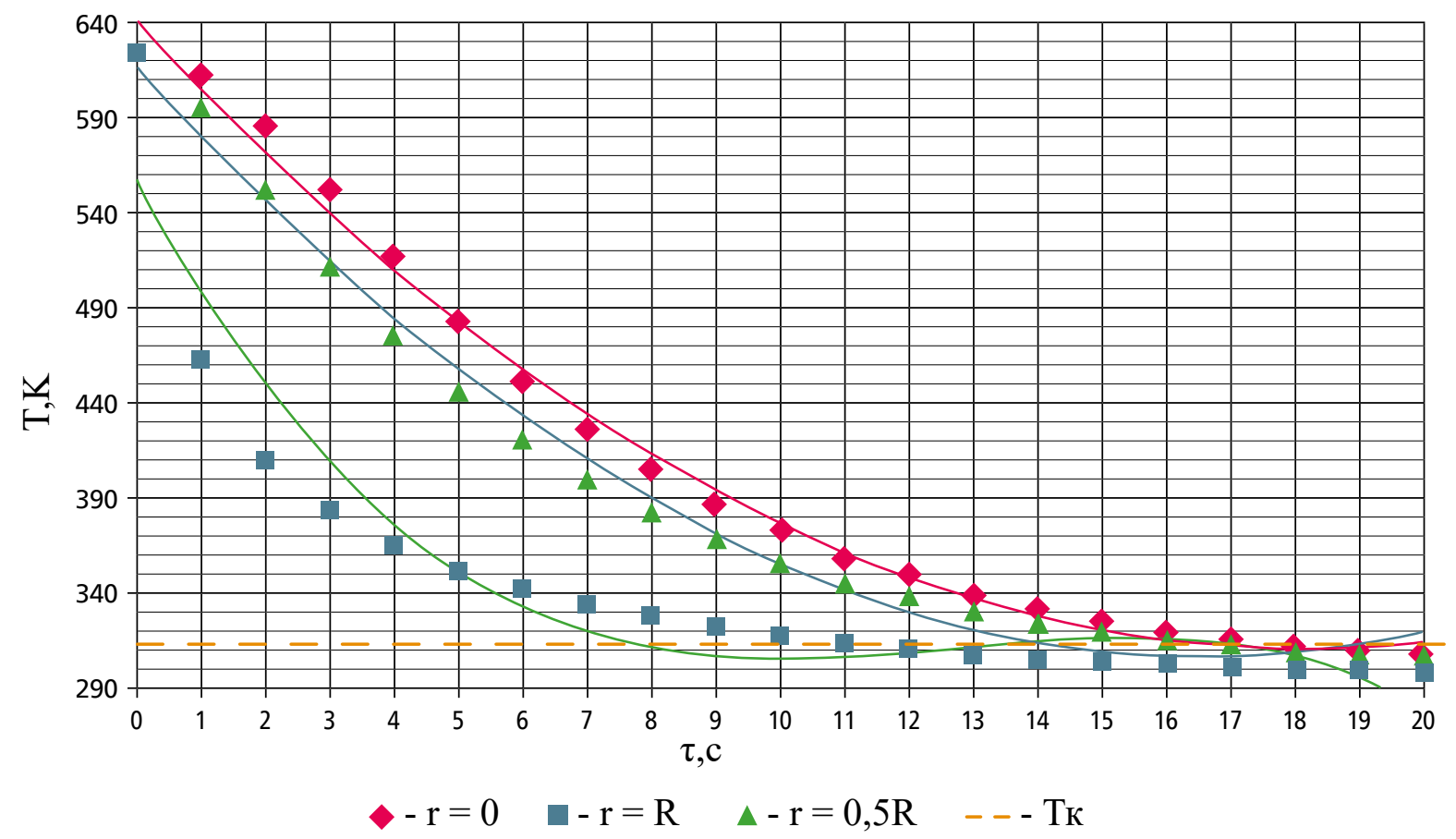

Рис. 5. Графік зміни температури гранули $T$ в часі $\tau$ 


\section{Висновки}

Показана необхідність дослідження процесу охолодження пористого гідроалюмосилікатного матеріалу після основних теплових процесів для подальшого пакування і надання товарного вигляду. Проведено моделювання процесу та його перевірка експериментальним шляхом із визначенням необхідного часу охолодження частинок одержаного матеріалу i, як наслідок, забезпечення перебування матеріалу протягом цього часу в класифікаторах псевдозрідженого шару. Представлена математична модель дозволяє $з$ достатньою точністю визначити час охолодження для частинок різного діаметра i температури.

\section{References}

1. Хвастухин, Ю.И., Собченко, В.В. Энергосбережение в производстве теплоизоляционных материалов / Технічна електродинаміка. Тематичний випуск. - 2003. - С. 96 - 99.

2. Кривенко, П.В., Пушкарева, К.К., Кочевих, М.О. Заповнювачі для бетону. - К. - 2001. - 400 с.
3. Костогриз, К.П., Хвастухін, Ю.І., Орлик, В.М., Собченко, В.В., Максимук, О.Б. Розвиток технології термічної обробки дисперсних матеріалів. Энерготехнологии и ресурсосбережение. - 2019. - № 4. C. 47 - 59.

4. Хвастухин, Ю.И., Эйне, И.А., Когута, Н.К., Роман, С.Н., Собченко, В.В. Получение в псевдоожиженном слое пористого материала - сиопора. Экотехнологии и ресурсосбережение. - 2002. - №5. C. 19 - 24

5. Гапонюк, М.М., Собченко, В.В. Дослідження процесу охолодження частинок спученого сиоліту. Кераміка: наука і життя. - 2015. - № 2(27). - С. 10 - 13. 6. Исаченко, В. П., Осипова, В. А., Сукомел, А. С. Теплопередача. Учебник для вузов. Букинист. - Изд.4, перераб. и доп. - М. - 1981. - 416 с.

7. Федоров, И.М. Теория и расчет процессов охлаждения во взвешенном состоянии, Госэнергоиздат. 1955. $-128 \mathrm{c}$.

8. Хвастухин, Ю.И., Собченко, В.В., Когута, Н.К., Роман, С.Н. Тепло- и массообмен при термообработке и вспучивании в псевдоожиженном слое. Экотехнологии и ресурсосбережение. - 2005. - № 4. C. $48-52$. 